\title{
Analysis of penetration loss of ultra high frequency band radio waves on trains
}

\author{
Masataka Hayashi ${ }^{a)}$, Yasuhiro Tsunemitsu, \\ and Toshiyuki Maeyama ${ }^{\text {b) }}$ \\ Faculty of Engineering, Graduate School, Takushoku University, \\ 815-1 Tatemachi, Hachioji-shi, Tokyo 193-0985, Japan \\ a)y3m313@st.takusyoku-u.ac.jp \\ b)tmaeyama@es.takusyoku-u.ac.jp
}

\begin{abstract}
The use of smartphones has increased the opportunity to communicate on trains. Therefore, the penetration loss by the train structure is an important consideration when designing the radio link in a mobile communications system. In this study, we evaluate the penetration loss of UHF band radio waves on a train. First, we analyzed the penetration loss on the train by electromagnetic field simulation. Then, we measured the penetration loss on the train and compared the results to those of the electromagnetic field simulation. The electromagnetic field simulation and measured results were found to be in good agreement.
\end{abstract}

Keywords: UHF-TV broadcasting waves, propagation characteristics, train cars, FDTD method, penetration loss

Classification: Electromagnetic theory

\section{References}

[1] T. Ito, N. Kita, S. Yokoyama and M. Ogasawara: IEICE General Conference, No. B (2008) 1.

[2] T. Hikage, A. Kitagawa, T. Nojima, W. Yamada and T. Sugiyama: IEICE General Conference, No. B (2010) 1.

[3] T. Hikage, Y. Irie, T. Nojima, W. Yamada and T. Sugiyama: IEICE Technical Report A.P2011-153 (2012) 43.

[4] M. Shirafune, T. Hikage, T. Nojima, W. Yamada and T. Sugiyama: IEICE Technical Report A.P2012-36 (2012) 35.

[5] EEM Inc: EEM-FDM (2011) http://www.e-em.co.jp/fdm/eem_fdm.htm.

[6] T. Sugo, M. Hayashi, T. Maeyama, S. Imai and N. Suzuki: IEICE Technical Report A.P2013-26 (2013) 59.

[7] M. Hayashi, M. Mori and T. Maeyama: IEICE Technical Report A.P2013-133 (2013) 47.

[8] Association of Japanese Private Railways: Railway Glossary - congestion rate (2013) http://www.mintetsu.or.jp/knowledge/term/96.html.

[9] K. Inomata, T. Matsunaga, M. Matsunaga and K. Uchida: ITE Technical Report, BCT2012-3 (2012) 9.

[10] T. Hikage, R. Okamura, T. Nojima, W. Yamada and T. Sugiyama: IEICE General Conference, No. B-1-25 (2011). 


\section{Introduction}

In recent years, communication in various places has become possible by the spread of smartphones. Moreover, users are likely to communicate with smartphones while travelling on a train. Therefore, the penetration loss caused by the train is an important parameter when designing the radio link in a mobile communications system. There are few examples of research on the reception characteristics of electromagnetic waves from a transmission tower, although the propagation characteristics on trains is examined by [1, 2, 3, 4]. Therefore, the penetration loss on the train is an important area of research. Thus, we focus on the penetration loss when the ultra high frequency (UHF) band radio waves penetrates into the train.

In this study, the transmitted radio waves in the cellular system are simulated by UHF band digital terrestrial television broadcasting waves. Cellular system of mobile telecommunications in the central area of Tokyo, the base station is set up on the building of about $20 \sim 30 \mathrm{~m}$, and a service area radius of the cellular system is about $200 \mathrm{~m}$. For example, if receiving radio waves at location of $200 \mathrm{~m}$ in the radius from the base station of height $20 \mathrm{~m}$, the angle parameter of the incoming waves becomes elevation angle about $6^{\circ}$ from ground. On the other hand, to cover the Kanto region in Japan, digital TV signals are transmitted from two towers: Tokyo Sky Tree (634 $\mathrm{m}$ tall) and Tokyo Tower (333 m tall). In order to receive the incoming waves of elevation angle about $6^{\circ}$, and receiving point should be away at $6.3 \mathrm{~km}$ in the radius from Tokyo Sky Tree. Therefore, if receiving point is a location away enough and line of sight from Tokyo Sky Tree and Tokyo Tower, the angle parameter of the radio waves in the cellular system can be simulated.

In this paper, we examined the loss when the UHF band radio waves penetrate a train. Specifically, for the purpose of analysis, the penetration loss, the train, and the passengers were suitably modeled. The results of our calculations are compared with actual measurements of the signal strength inside the train. As a result, we assume the penetration loss on the train as a radio link design parameter in mobile communication systems.

The paper is organized as follows. Section 2 describes the electromagnetic analysis model and section 3 describes the measurement method. Section 4 compares the analysis and the measurement results, and discusses the penetration loss. Finally, the research is summarized in section 5.

\section{Model for electromagnetic analysis}

We use the finite difference time domain (FDTD) method in our electromagnetic analysis [5]. The geometrical model used for the analysis is shown in Figs. 1-3. The body of the train is assumed to be made of a perfect electric conductor and the windows are assumed to be made of glass with a thickness of $5 \mathrm{~mm}$. The part where train cars are connected is made of nylon. The platform is set up next to the train, and the door of the train on the platform side is opened. The parameters of the materials involved in the analysis are shown in Table I.

The incoming waves from the two towers are simulated as plane waves with horizontal polarization. To analyze the effects of the people on the train, models of the human body in an upright position holding the handrail or the hanging strap, 
Table I. Analysis parameters.

\begin{tabular}{|c|c|}
\hline Frequency & $540 \mathrm{MHz}$ \\
\hline Conductivity of glass & $0.01 \mathrm{~S} / \mathrm{m}$ \\
\hline Relative permittivity of glass & 5 \\
\hline Conductivity of concrete & $10^{-4} \mathrm{~S} / \mathrm{m}$ \\
\hline Relative permittivity of concrete & 7 \\
\hline $\begin{array}{c}\text { Relative permittivity of } \\
\text { train connecting parts }\end{array}$ & 3.5 \\
\hline $\begin{array}{c}\text { Conductivity of a human body } \\
\text { Relative permittivity of } \\
\text { a human body }\end{array}$ & $0.74 \mathrm{~S} / \mathrm{m}$ \\
\hline
\end{tabular}

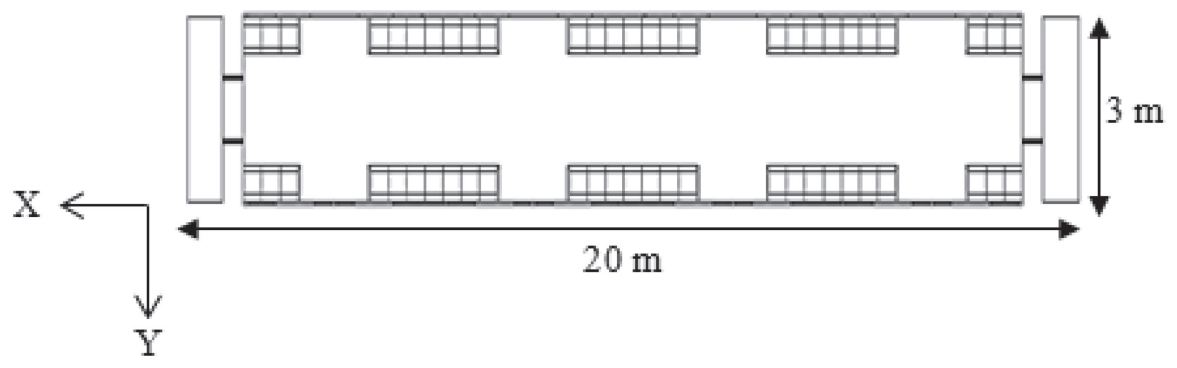

Fig. 1. Top view of the train model.

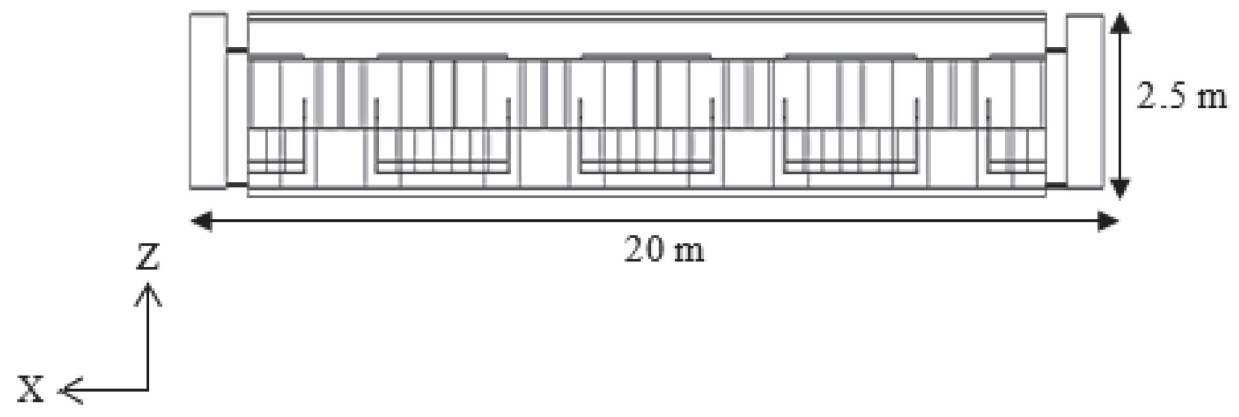

Fig. 2. Side view of the train model.

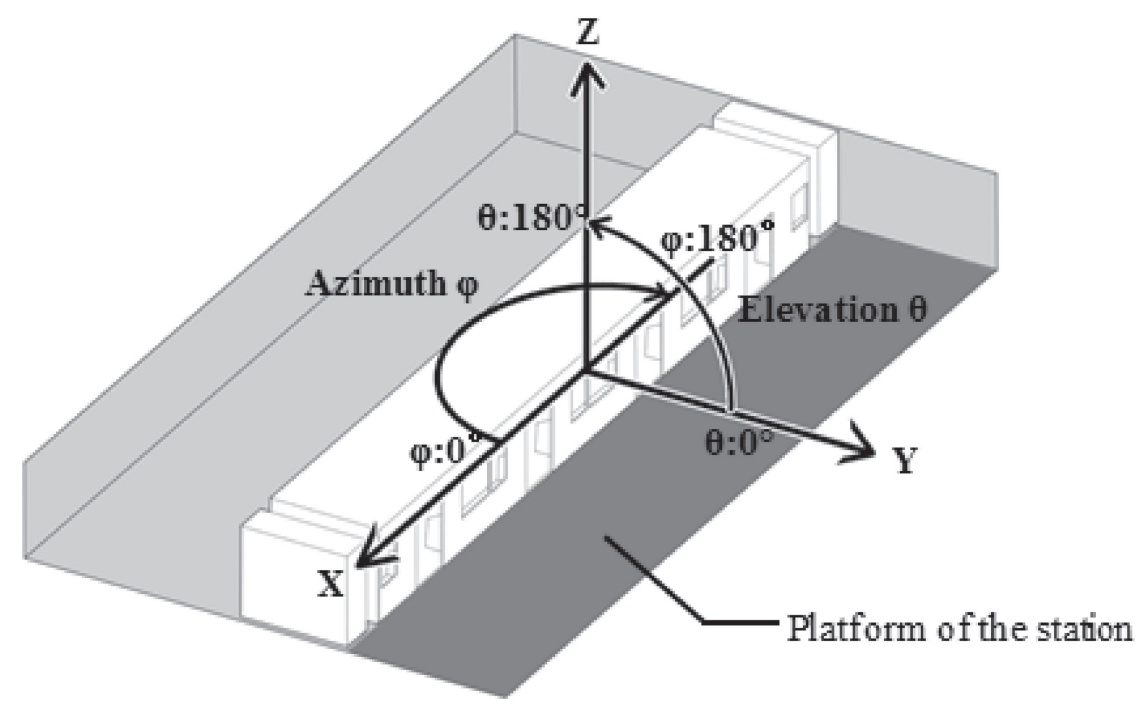

Fig. 3. Over view of the train model. 
and in a sitting posture were used. The model of the human body that we used in our analysis was developed in $[6,7]$. In the analysis, train occupancy was assumed to be $50 \%$ of the 150 -passenger capacity [8].

\section{Measurement of the signal strength}

We conducted our measurements on the Yamonote Line which covers the Tokyo metropolitan area. The penetration loss characteristic on the train was evaluated by comparing the results of measurements and electromagnetic field simulation. A map of the area is shown in Fig. 4. We selected measurement points of Shin-Ōkubo Station and Nishi-Nippori Station that had not been comparatively shielded by the building in the measurement location. Figs. 6, 7 show the incoming waves direction as viewed from the Shin-Ōkubo station platform and Nishi-Nippori station platform. In Figs. 6, 7, it is a situation in which the radio waves from Tokyo Sky Tree and Tokyo Tower reaches easily because the building has not been high density in the incoming wave direction.

As shown in Fig. 3, the arrival direction of the radio wave is represented by $\theta$ and $\varphi$. Table II shows the direction of arrival of radio waves in each station. These stations are away enough the distance from Tokyo Sky Tree and Tokyo Tower, and the angle parameter of the incoming waves are corresponding to the cellular system in the central area of Tokyo. Fig. 5 shows the measurement points inside and outside the train. When the train was stopped at the station, we measured the signal strength at points 1-6. In addition, when the train was not stopped at the station, we

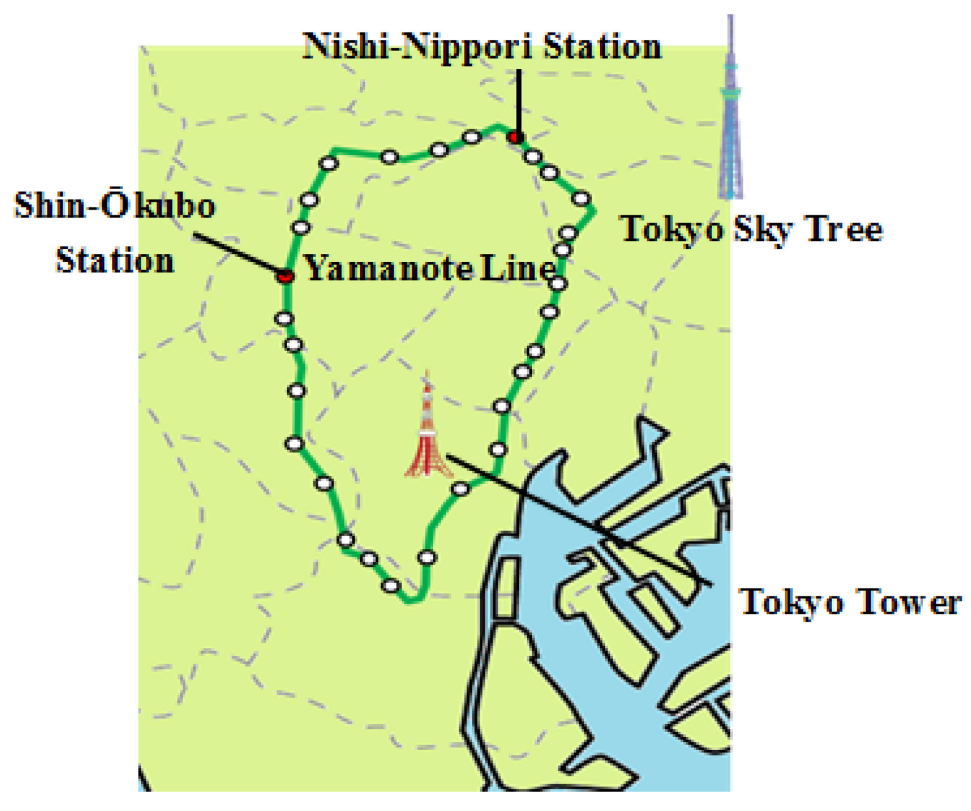

Fig. 4. Position of the towers and the line.

Table II. Angle of incidence of the radio waves for the train. 


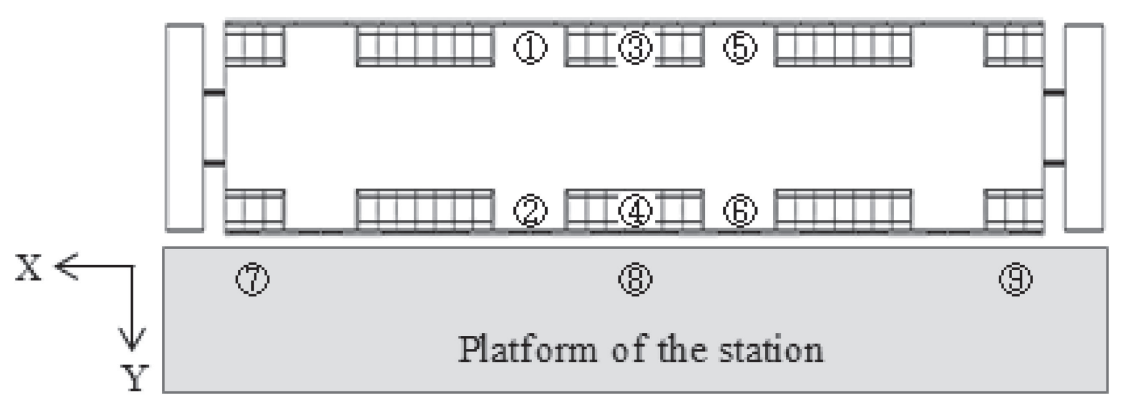

Fig. 5. Measurement points in the train and platform of the station.

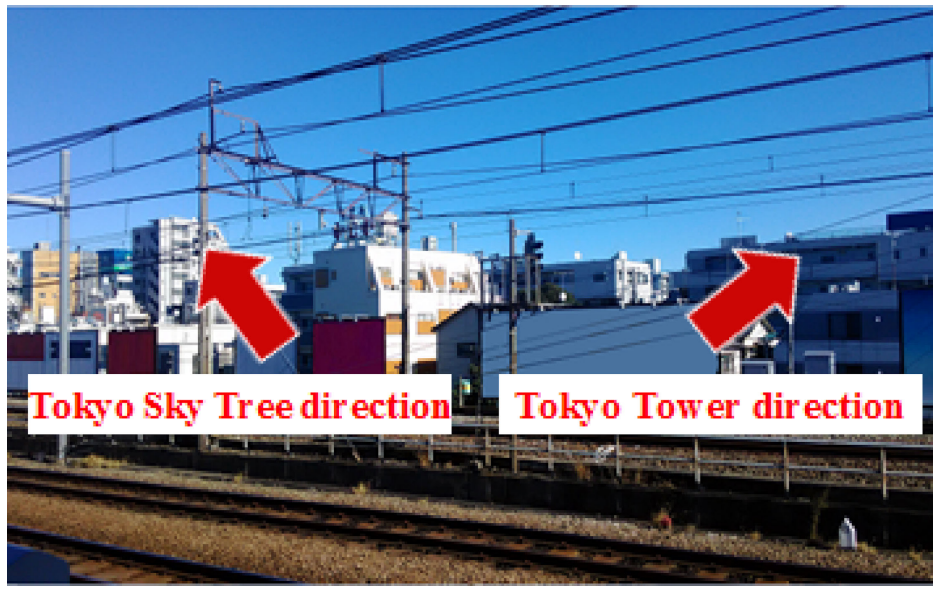

Fig. 6. Incoming wave direction as viewed from the Shin-Ōkubo station platform.

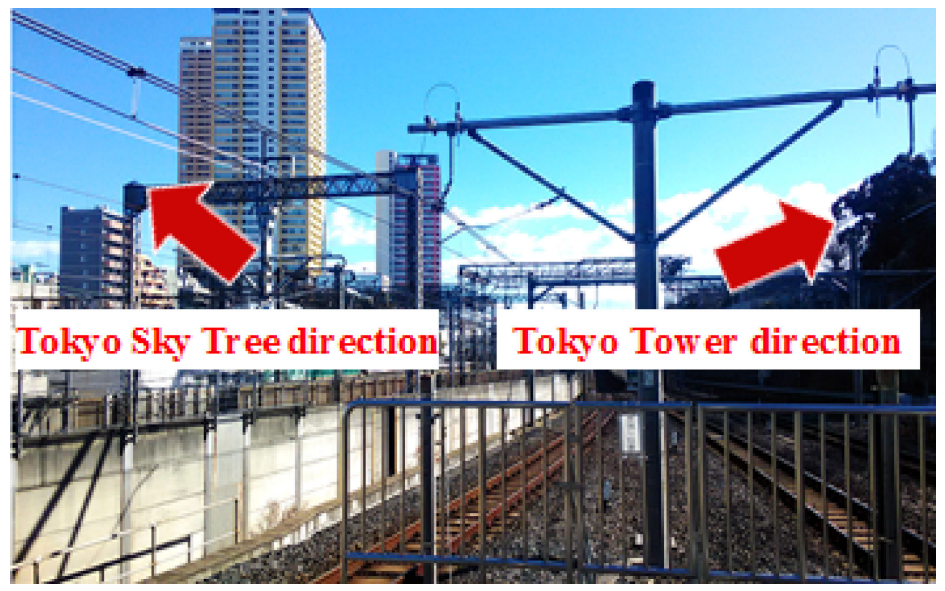

Fig. 7. Incoming wave direction as viewed from the Nishi-Nippori station platform.

measured the signal strength at points 7-9 on the platform. The equipment used to measure the electric field comprised a dipole antenna, designed for operation in the UHF band, and a portable spectrum analyzer. The antenna was held $1.5 \mathrm{~m}$ above the floor and the vehicle ride rate was estimated to be between $40 \%$ and $50 \%$. The penetration loss was calculated according to the difference between the mean value of the signal strength on the platform (points 7-9) and the signal strength at each measurement point in the train. Thus, the penetration loss is determined by comparing the signal strength in the train with the signal strength of the environment outside the train. 


\section{Analysis}

\subsection{Electromagnetic field simulation results}

The electromagnetic calculations were conducted using the angle parameters given in Table II. Figs. 8-11 show the distribution of the electromagnetic field. The vehicle ride rate is assumed to be $50 \%$. A human body model was placed at the seat and the door at both ends. Note that the figures are normalized to the calculated maximum value. As for the radio wave incident direction $\varphi$, the side of the train opposite the platform is $0^{\circ}-180^{\circ}$, and the platform side is $180^{\circ}-360^{\circ}$. The radio waves enter the train from the window and the open door. This is because the body of the train is made of metal.

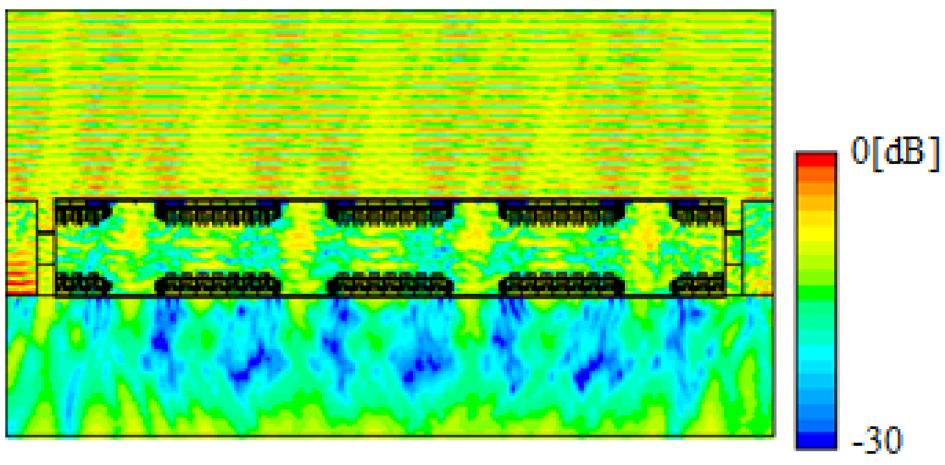

Fig. 8. Electric field distribution at Shin-Ōkubo station. (From Tokyo Tower: $\theta=3.4^{\circ}, \varphi=84^{\circ}$ )

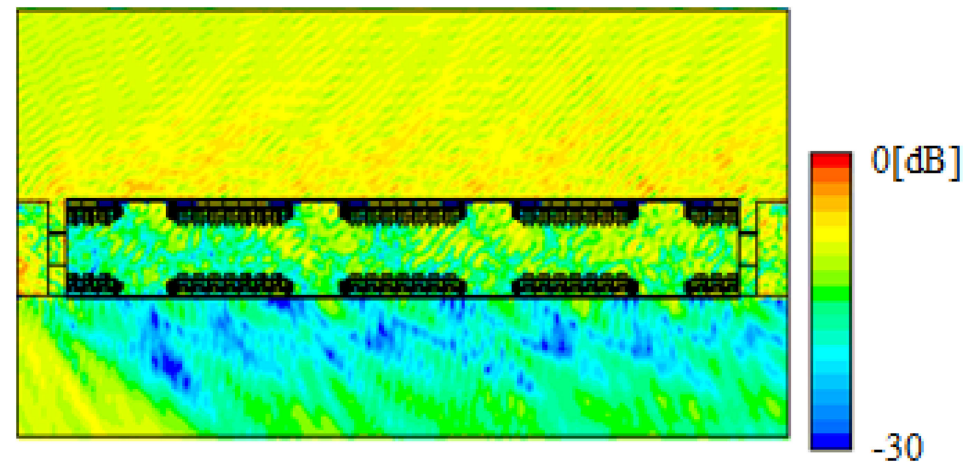

Fig. 9. Electric field distribution at Shin-Ōkubo station. (From Tokyo Tower: $\theta=5.5^{\circ}, \varphi=139^{\circ}$ )

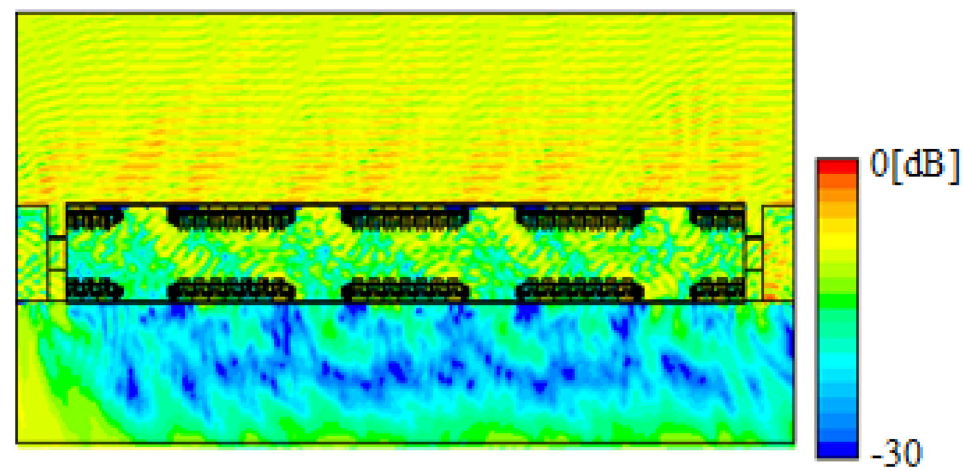




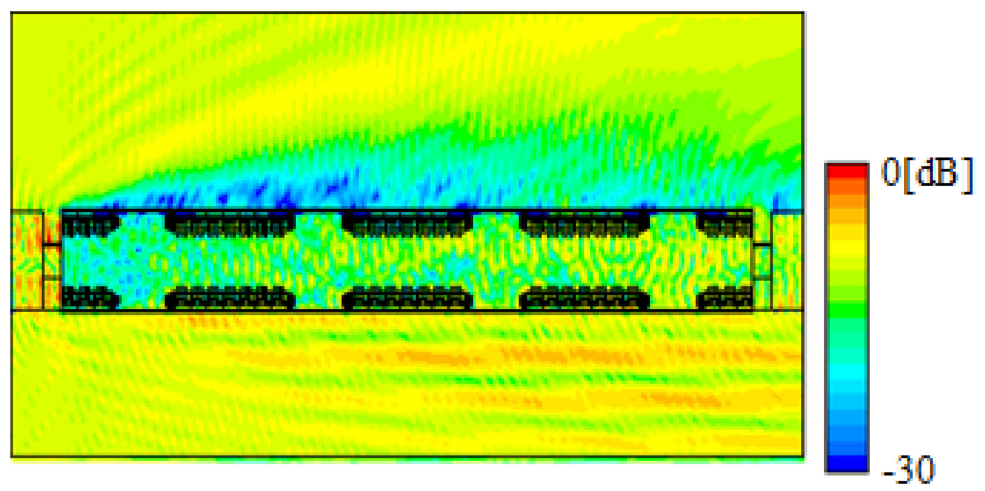

Fig. 11. Electric field distribution at Nishi-Nippori station.

(From Tokyo Tower: $\theta=4.2^{\circ}, \varphi=193^{\circ}$ )

In this simulations, the loss was confirmed when the coming wave penetrates the window [9]. Moreover, the passengers in front of the window caused the shielding and reflection of the radio waves [10].

\subsection{Comparison of electromagnetic field simulation values and measured values}

The results of the electromagnetic field simulation and measured penetration loss on the train are shown in Figs. 12, 13. The result of Shin-Ōkubo Station shown in Fig. 12, the simulation value and the measurement value became within about $10 \mathrm{~dB}$. Similarly, the result of Nishi-Nippori Station shown in Fig. 13, the simulation value and the measurement value became within about $7 \mathrm{~dB}$. Therefore, the differences between simulation and measurement results were less than $10 \mathrm{~dB}$ in all our assumed cases. Thus, the calculation of the penetration loss in an electromagnetic field simulation was effective.

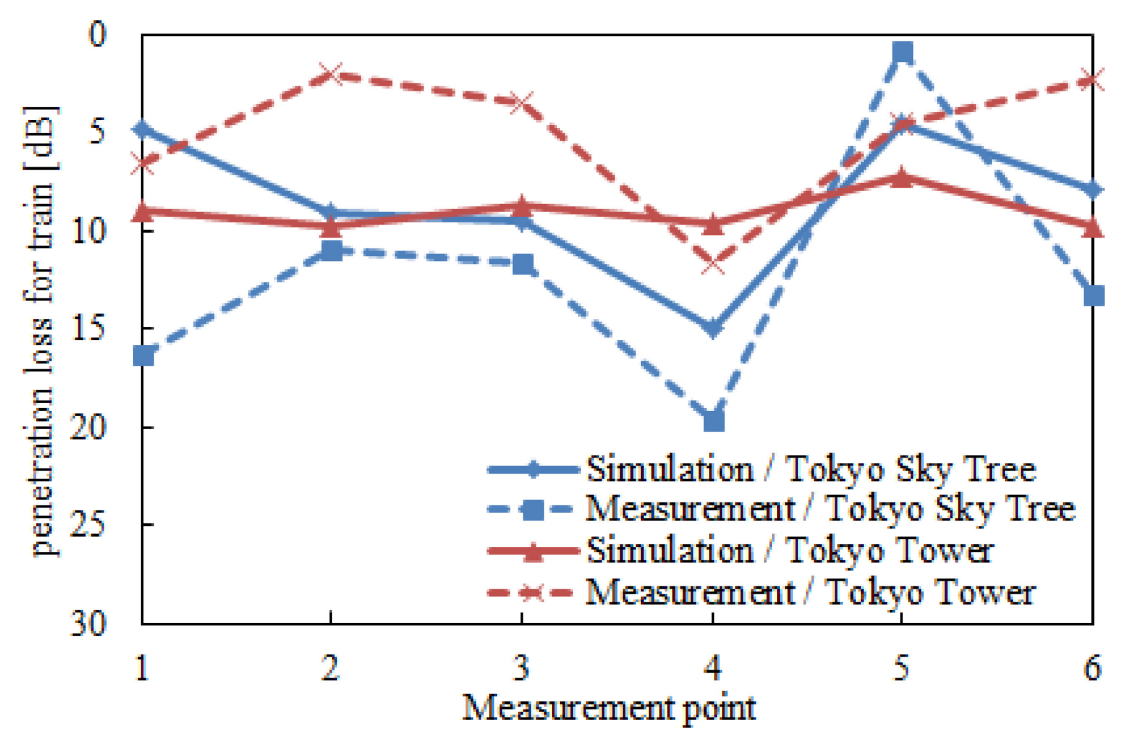

Fig. 12. Penetration loss at Shin-Ōkubo Station. 


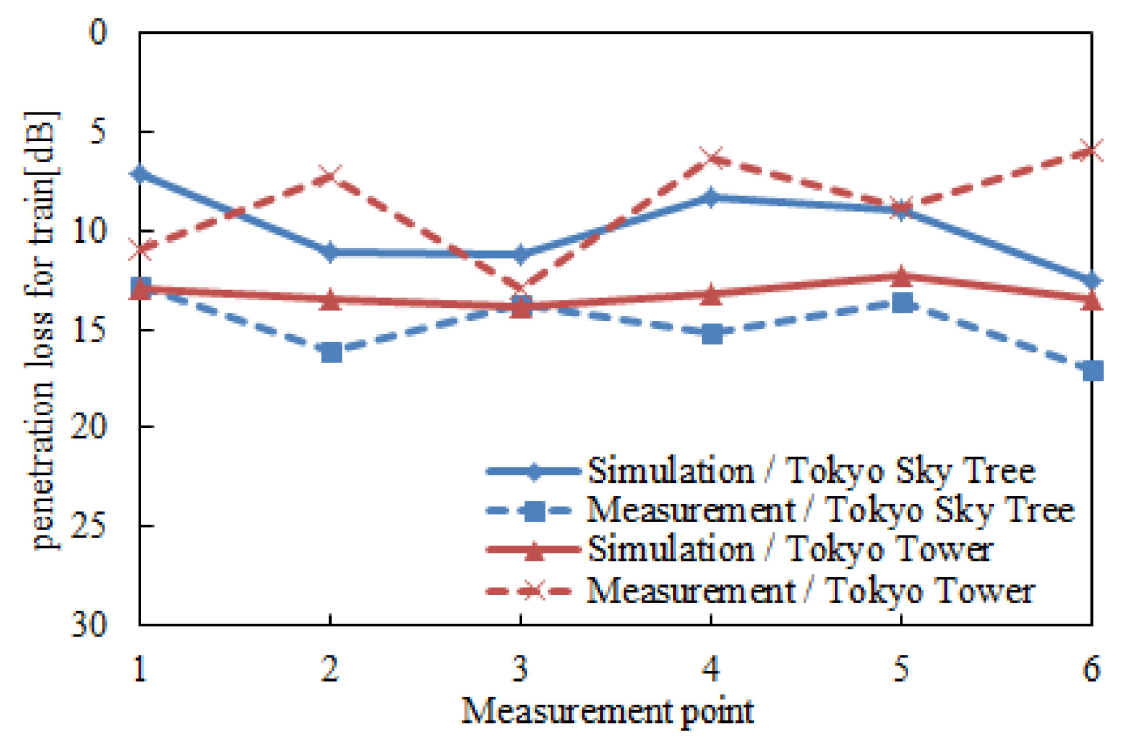

Fig. 13. Penetration loss at Nishi-Nippori Station.

\section{Conclusion}

As a radio link design parameter for mobile communications, the penetration loss by the train was verified by the electromagnetic field simulation and measurement. The calculation of the penetration loss by electromagnetic analysis used the FDTD method. This result corresponded well with the measurement result, the penetration loss of the train became about $5-15 \mathrm{~dB}$.

Thus, radio link design for mobile communications systems and digital terrestrial television broadcasting using the UHF band must consider the penetration loss in trains. However, the propagation loss parameter of radio link design should be calculated by the distance of the train and the base station. 